\title{
Effect of hyperketonemia on the diurnal patterns of energy-related blood metabolites in early-lactation dairy cows
}

\author{
C. R. Seely, ${ }^{1} \oplus$ K. D. Bach, ${ }^{1} \odot$ D. M. Barbano, ${ }^{2} \odot$ and J. A. A. McArt ${ }^{1 *}$ (두 \\ ${ }^{1}$ Department of Population Medicine and Diagnostic Sciences, College of Veterinary Medicine, Cornell University, Ithaca, NY 14853 \\ ${ }^{2}$ Department of Food Science, College of Agriculture and Life Sciences, Cornell University, Ithaca, NY 14853
}

\begin{abstract}
Most dairy cows experience a period of energy deficit in early lactation, resulting in increased plasma concentrations of nonesterified fatty acids (NEFA) and $\beta$-hydroxybutyrate (BHB). Our objectives were to determine (1) the diurnal variation in plasma BHB and NEFA, (2) the correlation between plasma NEFA and $\mathrm{BHB}$ when accounting for diurnal changes, and (3) the effect of hyperketonemia (HYK) on the diurnal pattern of blood metabolites. Jugular catheters were placed in 28 multiparous Holstein cows between 3 and 9 days in milk, and blood samples were collected every $2 \mathrm{~h}$ for $96 \mathrm{~h}$. Cows were retrospectively classified as HYK positive (HYK; $n=13$ ) if they had plasma BHB concentrations $\geq 1.2 \mathrm{mmol} / \mathrm{L}$ for $\geq 3$ study days, or HYK negative (non-HYK; $\mathrm{n}=15$ ) if they had plasma BHB concentrations $\geq 1.2 \mathrm{mmol} / \mathrm{L}$ for $\leq 2$ study days. Generalized linear mixed models were used to analyze concentrations of analytes over time and differences in metabolites between HYK groups. The correlation between total plasma NEFA and BHB was analyzed by calculating the area under the curve for plasma NEFA and BHB for all cows. Plasma NEFA reached a peak approximately $2 \mathrm{~h}$ before morning feed delivery, falling to a nadir in the late evening. Plasma BHB was at a nadir at the time of morning feed delivery, peaking $4 \mathrm{~h}$ later. We observed a strong positive correlation between daily plasma NEFA and BHB. Additionally, HYK cows had greater concentrations of plasma NEFA and BHB than non-HYK cows. The HYK cows also experienced a greater magnitude of change in BHB throughout the day than the non-HYK cows. Our results suggest that the time relative to feeding should be considered when analyzing plasma metabolites, as classification of energy status may change throughout a day.
\end{abstract}

Received May 20, 2020.

Accepted August 20, 2020.

*Corresponding author: jmcart@cornell.edu
Key words: hyperketonemia, energy status, $\beta$-hydroxybutyrate, nonesterified fatty acids

\section{INTRODUCTION}

During the transition from late pregnancy to early lactation, when energy requirements to support lactation are not met by the level of intake, dairy cows enter a state of energy deficit (Bell, 1995). To compensate for this energy deficit, cows mobilize adipose stores and release nonesterified fatty acids (NEFA) into circulation. The oxidation of NEFA within the liver can contribute to energy production; however, when concentrations of NEFA exceed hepatic oxidative capacity, ketone bodies are produced and exported into circulation (White, 2015). $\beta$-hydroxybutyrate, the predominant ketone body produced, is considered representative of total body ketone status in the dairy cow (Duffield, 2000) and can be used, to an extent, as a fuel source by some extrahepatic tissues. Although increases in circulating NEFA and BHB are part of the normal adaption to lactation, excessively elevated concentrations in blood have been associated with an increased risk for negative health events and decreased milk production (Ospina et al., 2010a; Chapinal et al., 2012; McArt et al., 2012).

Hyperketonemia (HYK), the excessive elevation of blood BHB, is not only associated with increased risk for the development of other diseases, but also presents a substantial economic burden to the producer. With an estimated total cost per case of $\$ 289$ (McArt et al., 2015), identifying individual cows with HYK is a laborious, yet important task. The benchmark method of HYK diagnosis is through laboratory quantification of blood BHB using enzymatic analysis (Oetzel, 2004). Similarly, the currently accepted method to accurately quantify blood NEFA is also through laboratory analysis. Several handheld meters have been developed that allow for accurate, cowside measurements of whole blood BHB (Bach et al., 2016; Sailer et al., 2018), but they still present considerable costs, especially when used as a whole-herd screening method for HYK. Thus, improving our knowledge of the optimal time for on- 
farm testing is necessary to truly understand the energy status of early-lactation cows.

The time of feed delivery (Blum et al., 1985) as well as feeding frequency (Eicher et al., 1999) are factors known to affect concentrations of blood NEFA and BHB. Past studies have highlighted a steady rise in blood NEFA in the late evening and early morning, leading up to the delivery of feed, with concentrations of BHB concurrently decreasing (Blum et al., 1985). Concentrations of NEFA and BHB can approximately double throughout a day, with a cow experiencing elevated concentrations at $1 \mathrm{~h}$, but returning to a physiologically normal level several hours later (Nielsen et al., 2003). Considering the diurnal variation in both blood metabolites, the time of blood sample collection relative to feeding might affect a cow's perceived energy status; a misdiagnosis could present further costs to producers and leave cows at an increased risk for the consequences associated with excessive energy deficit.

Therefore, our objectives were to determine (1) the diurnal variation in blood NEFA and BHB, (2) the correlation between plasma BHB and NEFA when accounting for diurnal changes, and (3) the effect of HYK on the diurnal patterns of blood metabolites in cows fed once per day.

\section{MATERIALS AND METHODS}

All procedures were approved by the Cornell University Institutional Animal Care and Use Committee (protocol no. 2018-0076). Our initial sample size calculation was determined with an interest in assessing the difference in milk BHB between cows experiencing normal and excessive energy deficit. Assuming a herd level HYK prevalence of $30 \%$ and controlling for type I and type II errors of 5 and $20 \%$, respectively, a sample size of 30 cows was required (data not shown) to detect a difference in milk BHB of $0.05 \mathrm{mmol} / \mathrm{L}$ between cows experiencing normal and excessive energy deficit, with an assumed mean milk BHB concentration of 0.10 $\pm 0.04 \mathrm{mmol} / \mathrm{L}$ (Santschi et al., 2016; Tatone et al., 2017). A posthoc power analysis was performed, and this sample size allowed us to detect a $0.30 \mathrm{mmol} / \mathrm{L}$ difference between cows experiencing normal and excessive energy deficit with $90 \%$ power while controlling for a type I error of $5 \%$, assuming a mean blood BHB concentration of $0.90 \pm 0.20 \mathrm{mmol} / \mathrm{L}$.

\section{Animals, Feeding, and Management}

We enrolled a total of 28 multiparous Holstein cows between 3 and 9 DIM on the following Mondays: June 3, June 10, June 17, and July 1 of 2019 at the Cornell
University Ruminant Center (Harford, NY). Following the morning milking at $0700 \mathrm{~h}$, cows were removed from the fresh pen and a 14-gauge $\times 140$-mm catheter (Abbocath-T, Hospira, Sligo, Ireland) was placed in the jugular vein. Prior to catheter placement, a $10 \times 10 \mathrm{~cm}$ area was clipped and scrubbed with povidone iodine and $70 \%$ isopropyl alcohol, and $2 \mathrm{~mL}$ of $2 \%$ lidocaine (Vet One, Boise, ID) was administered subcutaneously. The surgical site was scrubbed again with povidone iodine and $70 \%$ isopropyl alcohol, and the catheter was placed and flushed with a $10 \mathrm{IU} / \mathrm{mL}$ of $0.9 \%$ heparinized sterile saline solution (heparin: Sagent Pharmaceuticals, Schaumburg, IL; saline solution: Abbott Animal Health, Abbott Park, IL).

Cows were then moved to a tiestall facility and allowed ad libitum access to water and a TMR formulated to meet or exceed requirements of early-lactation dairy cattle (Table 1). Feed was delivered once a day at $0900 \mathrm{~h}$, and the amount fed was adjusted daily to allow for a minimum of $5 \%$ refusals. Cows were milked thrice daily at 0600,1400 , and $2200 \mathrm{~h}$, and individual cow milk yield was recorded at each milking using herd software. Catheters remained in place until $0600 \mathrm{~h}$ on Friday morning, at which time they were removed and the site scrubbed with povidone iodine. Following the morning milking on Friday, cows completed the study and were returned to the fresh pen. For the duration of the study, the Cornell University Ruminant Center personnel could test and treat cows with clinical signs of ketosis according to farm protocols; however, none were diagnosed as such.

Table 1. Ingredient and formulated diet composition offered to 28 multiparous Holstein cows between 3 and 14 DIM

\begin{tabular}{lc}
\hline Item & $\begin{array}{c}\text { \% of DM unless } \\
\text { otherwise indicated }\end{array}$ \\
\hline Ingredient & \\
Corn silage & 45.69 \\
Grass hay & 17.04 \\
Concentrates & 37.27 \\
Formulated nutrient composition & \\
DM, \% & 37.8 \\
NE, Mcal/kg & 1.80 \\
$\mathrm{CP}$ & 16.6 \\
$\mathrm{ADF}$ & 16.7 \\
aNDF & 23.2 \\
$\mathrm{Starch}$ & 27.4 \\
$\mathrm{Ether} \mathrm{extract}$ & 4.87 \\
$\mathrm{Ash}$ & 7.31 \\
$\mathrm{Ca}$ & 0.75 \\
$\mathrm{P}$ & 0.32 \\
$\mathrm{Mg}$ & 0.30 \\
$\mathrm{~K}$ & 1.39 \\
$\mathrm{~S}$ & 0.23 \\
$\mathrm{Na}$ & 0.46 \\
$\mathrm{Cl}$ & 0.46 \\
\hline
\end{tabular}




\section{Sample Collection and Analysis}

Beginning at $1500 \mathrm{~h}$ on the day of enrollment (Monday), venous blood samples were obtained from the jugular catheter and collected every $2 \mathrm{~h}$ thereafter until completion of the study; the final blood sample was drawn on Friday at $0500 \mathrm{~h}$. At every sampling time point, $10 \mathrm{~mL}$ of blood were collected into an evacuated tube containing EDTA (Becton Dickinson, Franklin Lakes, NJ) for the separation of plasma. Blood samples were immediately placed on ice. Within $30 \mathrm{~min}$ of collection, samples were centrifuged at $2,800 \times g$ at $4^{\circ} \mathrm{C}$ for $20 \mathrm{~min}$, and plasma was aliquoted in duplicates into 2-mL microcentrifuge tubes (Labcon North America, Petaluma, CA) and stored at $-80^{\circ} \mathrm{C}$ until analysis.

Plasma was analyzed for BHB and NEFA using commercially available kits (BHB: D-3 Hydroxybutyrate Ranbut, Randox Laboratories, Antrim, UK; NEFA: HR Series NEFA-HR, Wako Diagnostics, Mountain View, CA) on a Roche Cobas 6000 series, c501 Clinical Chemistry Automated Analyzer (Roche Diagnostics, Indianapolis, IN) at the New York State Animal Health Diagnostic Center (Ithaca, NY). The inter- and intraassay coefficients of variation for BHB were $2.6 \%$ and $1.6 \%$, respectively, and the inter- and intra-assay coefficients of variation for NEFA were both $1.7 \%$.

\section{Statistical Analysis}

Descriptive statistics were generated using the FREQ procedure of SAS (v. 9.4, SAS Institute, Cary, NC). All graphs were created using Microsoft Excel (2018, Microsoft Corp., Redmond, WA). Prior to statistical analysis of plasma metabolites, cows were retrospectively classified into HYK groups based on their daily mean plasma BHB concentration using Microsoft Excel (2018, Microsoft Corp.). If the daily average was $\geq 1.2$ $\mathrm{mmol} / \mathrm{L}$, the cow was deemed as HYK positive for the day. If a cow was HYK positive for $\geq 3$ study days, they were assigned to the HYK group for analysis. Cows that were HYK positive for $\leq 2$ study days were assigned to the non-HYK group.

Concentrations of analytes over time were analyzed using generalized linear mixed models created through the MIXED procedure of SAS. Models were developed to assess the (1) changes in BHB and NEFA concentrations over time, (2) differences in BHB and NEFA concentrations and milk yield between HYK groups, and (3) differences between maximum and minimum BHB and NEFA concentrations by HYK group. Multiple measurements over time were analyzed using the REPEATED statement of SAS. Models analyzing the change in metabolites over time included the random effect of cow and the fixed effect of time. The fixed effect of time represented all sampling time points $(\mathrm{n}=44)$. Models analyzing the difference in metabolites between HYK groups included the random effect of cow and the fixed effects of HYK group, time, and the interaction of HYK group $\times$ time. For each model, the following covariance structures were tested and the model with the lowest Akaike's information criterion was selected: compound symmetry, unstructured, autoregressive (1), and Toeplitz. The Toeplitz covariance matrix resulted in the lowest Akaike's information criterion for all models. To improve the normality of residuals, the following transformations were made: $\log _{10}$ of plasma $\mathrm{BHB}$ and the fourth root of plasma NEFA. All means of plasma BHB and NEFA presented hereafter represent the backtransformed means \pm their associated $95 \%$ confidence intervals. Means were considered different at $P \leq 0.05$ with a tendency for difference at $0.10 \geq P>0.05$.

To capture data over time for the entirety of the study period, the area under the curve (AUC) was calculated for both plasma NEFA and BHB for the 96-h sampling period for each cow using the trapezoid, total area calculation as described by Cardoso et al. (2011). The correlation between plasma NEFA and BHB AUC was analyzed using the CORR procedure of SAS.

\section{RESULTS}

The mean DIM at enrollment for all cows was $6.1 \pm 2$ $\mathrm{d}$, and median parity was 3 and ranged from 2 to 6 . The mean DIM at enrollment for HYK cows $(\mathrm{n}=13)$ was $5.6 \pm 2.2 \mathrm{~d}$; median parity was 3 and ranged from 2 to 6 . The mean DIM at enrollment for non-HYK cows (n $=15)$ was $6.5 \pm 1.8 \mathrm{~d}$; median parity was 3 and ranged from 2 to 5 . The HYK cows had an average daily BHB concentration $\geq 1.2 \mathrm{mmol} / \mathrm{L}$ for $4 \pm 0.8 \mathrm{~d}$, and the nonHYK cows had an average daily BHB concentration $\geq 1.2 \mathrm{mmol} / \mathrm{L}$ for $0.5 \pm 0.7 \mathrm{~d}$. Additionally, the HYK cows had BHB concentrations $\geq 1.2 \mathrm{mmol} / \mathrm{L}$ for $71 \%$ of the study period, whereas the non-HYK cows had BHB concentrations $\geq 1.2 \mathrm{mmol} / \mathrm{L}$ for $18 \%$ of the study period.

Plasma concentrations of BHB changed over time $(P$ $<0.001$; Figure 1), and by design, plasma BHB was different between HYK groups $(P<0.001)$. We observed greater mean concentrations of plasma BHB in the HYK group $(1.57 \mathrm{mmol} / \mathrm{L}, 95 \% \mathrm{CI}=1.48$ to 1.67 $\mathrm{mmol} / \mathrm{L})$ than the non-HYK group $(0.91 \mathrm{mmol} / \mathrm{L}, 95 \%$ $\mathrm{CI}=0.86$ to $0.96 \mathrm{mmol} / \mathrm{L}$ ). Additionally, the difference in amplitude between the maximum and minimum daily plasma BHB concentrations differed between the HYK and non-HYK groups $(P=0.003)$, with HYK cows experiencing a greater magnitude of change in plasma BHB throughout the day than non-HYK cows (HYK maximum $=2.48 \pm 0.2 \mathrm{mmol} / \mathrm{L}, \mathrm{HYK}$ minimum $=$ 
A)

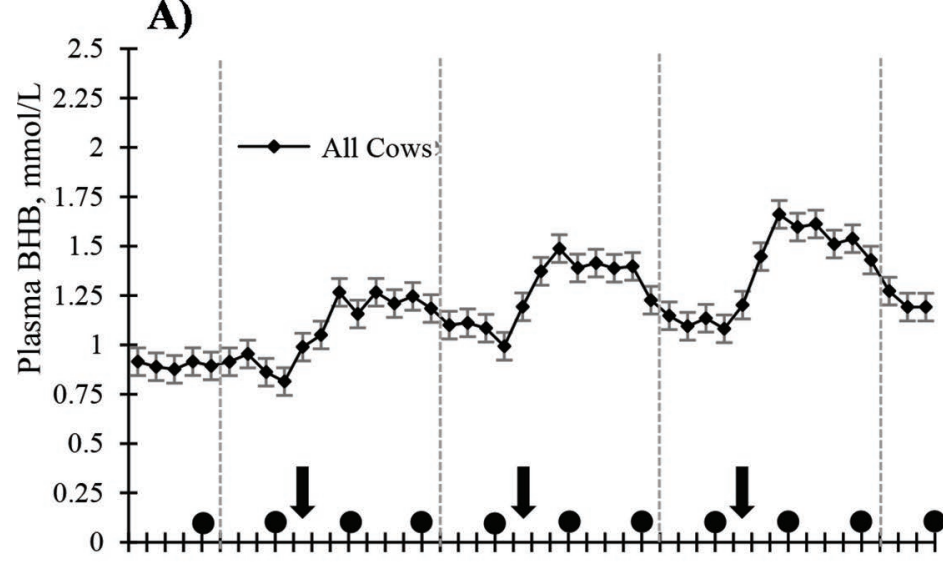

1.2 C)

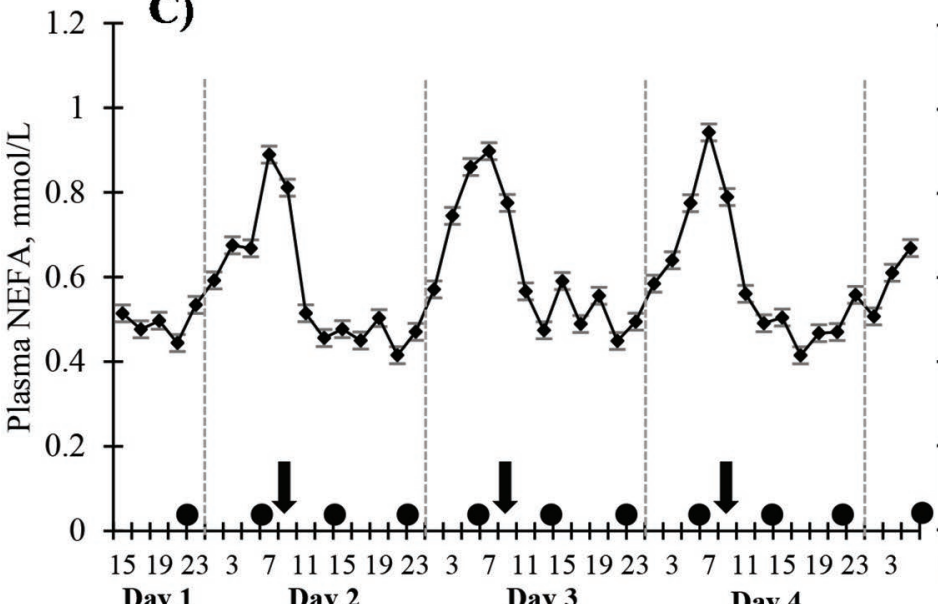

B)

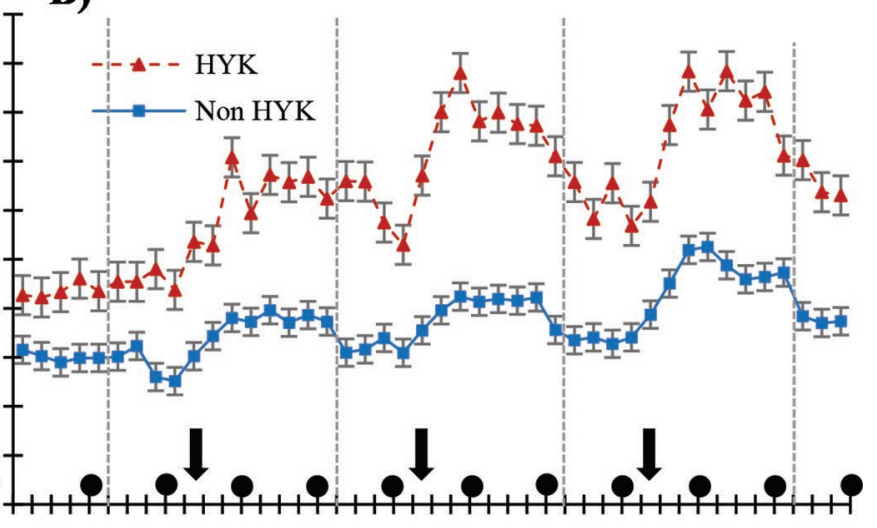

D)

Figure 1. Plasma metabolites for multiparous Holstein cows ( $\mathrm{n}=28$ ) between 3 and 14 DIM fitted with jugular catheters and sampled

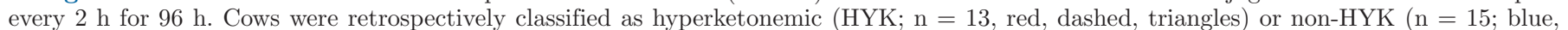

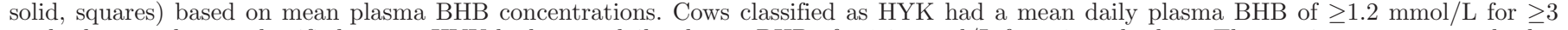

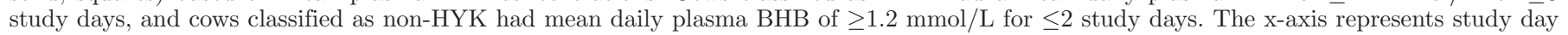

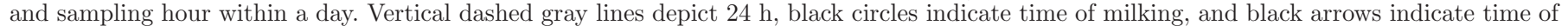

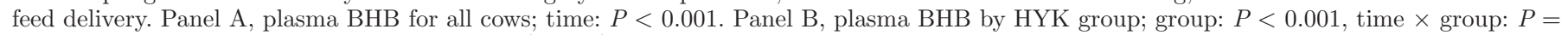

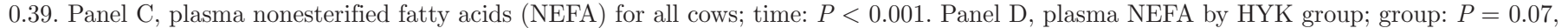
time $\times$ group: $P=0.42$.

$1.27 \pm 0.15 \mathrm{mmol} / \mathrm{L}, \mathrm{HYK}$ amplitude of change $=1.2$ \pm 0.19 , non-HYK maximum $=1.41 \pm 0.20 \mathrm{mmol} / \mathrm{L}$, non-HYK minimum $=0.63 \pm 0.15 \mathrm{mmol} / \mathrm{L}$, non-HYK amplitude of change $=0.95 \pm 0.18$ ) .

Concentrations of plasma NEFA were different across time $(P<0.001$; Figure 1$)$, and HYK cows tended to have greater concentrations of plasma NEFA than the non-HYK group $(P=0.07 ; 0.65 \mathrm{mmol} / \mathrm{L}, 95 \% \mathrm{CI}=$ 0.62 to $0.67 \mathrm{mmol} / \mathrm{L}$ and $0.51 \mathrm{mmol} / \mathrm{L}, 95 \% \mathrm{CI}=0.50$ to $0.54 \mathrm{mmol} / \mathrm{L}$, respectively). The amplitude of daily change in plasma NEFA was similar between HYK and non-HYK cows $(\mathrm{HYK}$ maximum $=1.24 \pm 0.1 \mathrm{mmol} / \mathrm{L}$, HYK minimum $=0.43 \pm 0.05 \mathrm{mmol} / \mathrm{L}, \mathrm{HYK}$ amplitude of change $=0.96 \pm 0.14$, non-HYK maximum $=$ $1.02 \pm 0.09 \mathrm{mmol} / \mathrm{L}$, non-HYK minimum $=0.31 \pm$
$0.05 \mathrm{mmol} / \mathrm{L}$, non-HYK amplitude of change $=0.85 \pm$ $0.13 ; P=0.30)$.

The relationship of cumulative plasma $\mathrm{BHB}$ and NEFA concentrations over time were represented by calculating the AUC of each metabolite for the duration of the study for each cow. Total BHB was positively correlated with total NEFA $(P<0.001, \mathrm{r}=0.81$; Figure 2). One cow was a statistical outlier with plasma NEFA and BHB AUC more than 2 standard deviations greater than the sample mean. When this cow was removed from the data set, the correlation between plasma NEFA and BHB for the entirety of the study period was $0.38(P=0.04)$.

Milk yield tended to increase within a study week $(P=0.07)$. Additionally, the non-HYK cows tended 


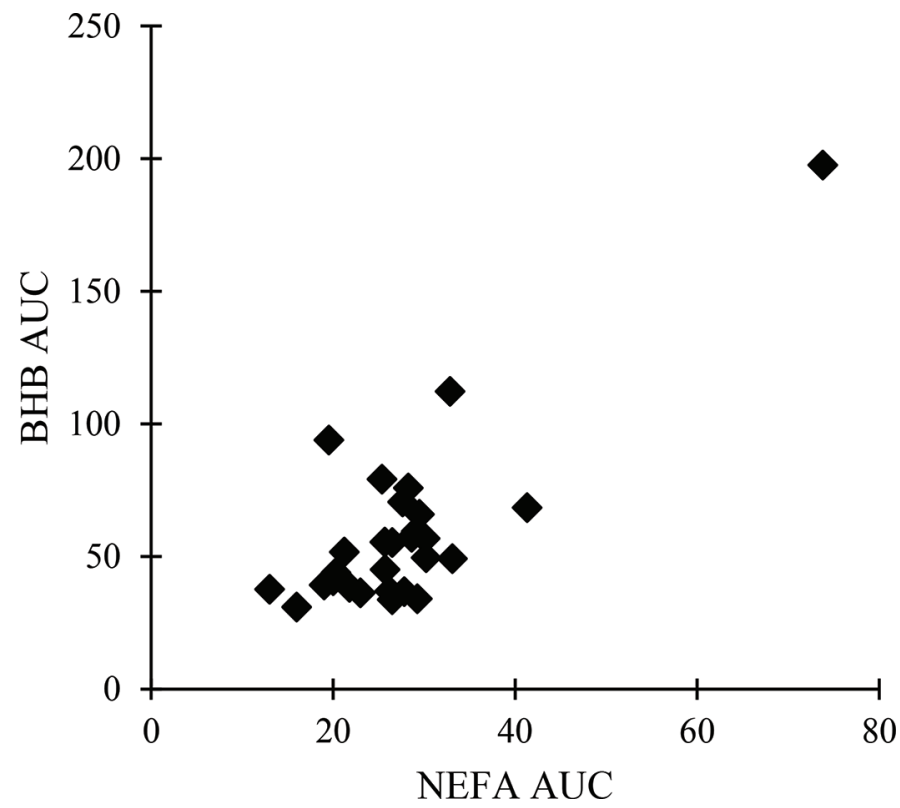

Figure 2. Correlation of plasma BHB and nonesterified fatty acid (NEFA) concentrations calculated as area under the curve (AUC) for 28 multiparous Holstein cows between 3 and 14 DIM, sampled every 2 $\mathrm{h}$ for $96 \mathrm{~h}(P<0.001 ; \mathrm{r}=0.81)$.

to produce more milk than the HYK cows $(P=0.06$; $13.8 \pm 0.6 \mathrm{~kg} /$ milking and $12.1 \pm 0.2 \mathrm{~kg} /$ milking, respectively).

\section{DISCUSSION}

In our study, we aimed to understand the diurnal variation in plasma BHB and NEFA and how they were affected by HYK. Additionally, we sought to explore the correlation between plasma BHB and NEFA when diurnal changes were considered. We consistently observed daily peaks in plasma NEFA $2 \mathrm{~h}$ before feed delivery. Nielsen et al. (2003) witnessed a similar peak in plasma NEFA $1 \mathrm{~h}$ before feed delivery when blood was sampled hourly for $24 \mathrm{~h}$. The increase in plasma NEFA immediately leading up to feed delivery, realized in our study and others (Blum et al., 1985, 2000; Nielsen et al., 2003), is likely the result of decreased feed intake during the overnight hours (DeVries et al., 2003).

When the available NEFA exceed hepatic oxidative capacity, they can instead be partially oxidized in the liver to ketone bodies and re-exported into circulation. The concentrations of BHB that we observed in the overnight hours are likely representative of hepatic BHB production, as intake is low and adipose stores are mobilized. Contrary to the peak in plasma NEFA observed before feeding, plasma BHB reached a daily nadir at this time. Instead, the highest concentrations of plasma BHB occurred $4 \mathrm{~h}$ after feeding. Our observa- tion supports previous work that also saw a nadir in plasma BHB at the time of morning feed delivery, with concentrations peaking in the following hours (Mashek et al., 2001; Nielsen et al., 2003). This is likely due to the ruminal production of BHB from volatile fatty acids (Heitmann and Fernandez, 1986). When Mahrt et al. (2014) continuously fed dairy cows, diurnal variation in plasma BHB was effectively mitigated, and cows had consistent concentrations of plasma BHB throughout the day. Similarly, when Herrick et al. (2017) infused butyrate into the rumens of mid-lactation cows, they observed a steady rise in plasma BHB immediately after the infusion, with a peak in plasma BHB achieved 4 $\mathrm{h}$ after dosing. Their findings also suggest that there is a limit to the alimentary production of BHB, as plasma BHB did not increase linearly with increased concentrations of butyrate dosed into the rumen. The diurnal patterns of BHB that we observed are well explained by the balance between ruminal and hepatic BHB production.

Hyperketonemic status affected concentrations of both plasma NEFA and BHB. As expected, cows classified as HYK had greater concentrations of plasma NEFA and BHB compared with non-HYK cows. Both groups experienced similar diurnal patterns of plasma metabolites; however, the magnitude of change of each metabolite within a day was different depending on HYK status. The HYK cows had an approximately 2 -fold greater difference in amplitude between daily maximum and minimum concentrations of plasma BHB compared with the non-HYK cows. This could potentially be due to differences in hepatic oxidative capacity between the 2 groups. Previous work has demonstrated that cows experiencing HYK have decreased hepatic expression of acetyl-Coenzyme A acetyltransferase 2 and 3-hydroxyacyl-CoA dehydrogenase, 2 enzymes involved in fatty acid degradation and oxidation within hepatocytes, thus limiting their potential to utilize NEFA for energy production and instead favoring partial oxidation to BHB (Murondoti et al., 2004; Xu et al., 2010). However, the reason for this difference cannot be determined from our analysis and warrants further investigation.

The potential difference in hepatic oxidative capacity between the HYK and non-HYK cows is further supported by the daily changes in plasma NEFA seen in the 2 groups. Although the HYK cows had overall greater concentrations of plasma NEFA, the magnitude of daily change was relatively similar between the 2 groups. The HYK cows experienced a $0.1 \mathrm{mmol} / \mathrm{L}$ greater difference between daily maximum and minimum NEFA than the non-HYK cows. Furthermore, both groups had average plasma NEFA concentrations lower than $0.70 \mathrm{mmol} / \mathrm{L}$, the commonly accepted threshold of plasma NEFA 
concentrations associated with negative health events (Ospina et al., 2010a; Chapinal et al., 2011). Taken together, this suggests that both groups mobilized similar amounts of adipose stores and were faced with biologically similar concentrations of plasma NEFA, and the non-HYK cows were more efficiently able to use the available NEFA for energy production as opposed to their partial oxidation to BHB. However, we were unable to differentiate between hepatic oxidative capacity and adipose tissue mobilization with our study design.

The association of elevated plasma NEFA and BHB with negative health events and decreased production is well established (Ospina et al., 2010a,b; Chapinal et al., 2012); however, to date, the metabolites are weakly associated. When Ospina et al. (2013) collected a single blood sample from cows between 3 and 14 DIM and assessed the correlation of NEFA and BHB, they obtained a correlation coefficient (r-value) of 0.18 , suggesting that the 2 metabolites were not well associated even when sampled at the same time. McCarthy et al. (2015) attempted to further explore the correlation between NEFA and BHB by calculating the AUC of total NEFA and BHB from 269 multiparous cows, sampled simultaneously for NEFA and BHB thrice weekly for the first $3 \mathrm{wk}$ of lactation. Despite the large sample size and extended sampling period, $\mathrm{r}$ was only 0.26 . Using a similar method to McCarthy et al. (2015) but adjusting for the diurnal relationship between the 2 metabolites, we obtained an r-value of 0.81 when we compared the total AUC for NEFA and BHB, a correlation coefficient greater than those previously reported. Our finding suggests that by capturing the daily fluctuations in plasma NEFA and BHB through our continuous sampling scheme, the variation in one metabolite is more accurately described by the other. As blood samples from both Ospina et al. (2013) and McCarthy et al. (2015) were taken in the morning before feed delivery and samples were submitted simultaneously for NEFA and BHB, these samples likely captured the daily peak in NEFA and nadir of BHB, thus reducing their correlation.

However, 1 cow in our data set did have higher total concentrations of plasma NEFA and BHB than her counterparts and was a suspected outlier. We chose to leave the suspected outlier in our final analysis because the cow showed no clinical signs of disease during the time of sample collection and maintained high levels of milk production. This cow was representative of a subgroup of cows present in every high-producing herd that experience elevated plasma concentrations of NEFA and BHB with no outward negative signs. Additionally, our analysis only included 28 animals, and with the inclusion of more animals, we would likely ob- serve more cows with concentrations of plasma NEFA and BHB similar to the suspected outlier.

Considering the biochemical origins of both metabolites and the lag between the daily peak and nadir of plasma NEFA and BHB, it is logical that we observed an increased association between the 2 metabolites when we accounted for diurnal variation. Despite the increased correlation that we observed between plasma NEFA and BHB, the 2 metabolites should not be used interchangeably as a marker of a cow's energy status. In many sampling schemes, blood samples are only collected once per day, likely capturing one metabolite at its peak and the other at its nadir. Therefore, when analyzing results of plasma analysis, the diurnal pattern of each metabolite should be considered.

Our study supports previous work by Blum et al. (2000) and Nielsen et al. (2003), which suggest that the time relative to feeding affects plasma BHB and NEFA concentrations; therefore, it is important to consider time relative to feeding when analyzing metabolites, especially for the purpose of disease diagnosis. Additionally, to our knowledge, no other study has classified cows as HYK based on as extensive of a sampling scheme as ours. We chose our HYK classification method as an attempt to best capture the energy status of the cow, as opposed to a snapshot in time, as many other classification and diagnosis schemes represent. Had we classified cows as HYK based on a single time point, we would have risked misclassifying cows depending on the time of day that samples were collected because plasma BHB follows a very consistent diurnal pattern. Our findings suggest that the time of sample collection relative to feed delivery should be considered when monitoring cows for HYK.

Even when time relative to feeding is considered, concentrations of plasma metabolites vary substantially throughout a day and are not consistent hourto-hour. Past work has shown that patterns of milk BHB and blood BHB are relatively similar when both are sampled simultaneously every $2 \mathrm{~h}$ for $26 \mathrm{~h}$ (Andersson and Lundström, 1984), and estimates of milk BHB concentrations might represent the average total body ketone status during the hours between milkings. For this reason, milk estimates might offer a more stable estimate of a cow's energy status. However, the relationship between estimates of milk constituents and their concentrations in blood has yet to be fully described and warrants further investigation.

\section{CONCLUSIONS}

Our study demonstrated important and consistent diurnal patterns in plasma BHB and NEFA. The ampli- 
tude in change between daily maximum and minimum concentrations of plasma metabolites was affected by HYK status. Additionally, we observed a strong positive correlation between plasma NEFA and BHB when we accounted for the diurnal variation in the 2 metabolites. Our results indicate that time relative to feeding should be considered when analyzing concentrations of blood metabolites and suggest that a single blood sample may not accurately represent a cow's energy status in early lactation.

\section{ACKNOWLEDGEMENTS}

Our study was funded by the USDA National Institute of Food and Agriculture Hatch project no. 1017096. The authors thank Colby Castle, Allison Kerwin, Margaret Kirby, Isabella Knecht, Franco Leal-Yepes, and Regina Martinez (Cornell University, Ithaca, NY) for their assistance with catheter placement and sample collection. We also thank Charlene Ryan, Lisa Furman, Greg Johnson (Cornell University), and the staff of the Cornell University Ruminant Center for their assistance with cow handling and care during the study. The authors state no conflicts of interest.

\section{REFERENCES}

Andersson, L., and K. Lundström. 1984. Milk and blood ketone bodies, blood isopropanol and plasma glucose in dairy cows; methodological studies and diurnal variations. Zentralbl. Veterinärmed. A 31:340-349. https://doi.org/10.1111/j.1439-0442.1984.tb01292.x.

Bach, K. D., W. Heuwieser, and J. A. A. McArt. 2016. Technical note: Comparison of 4 electronic handheld meters for diagnosing hyperketonemia in dairy cows. J. Dairy Sci. 99:9136-9142. https://doi .org/10.3168/jds.2016-11077.

Bell, A. W. 1995. Regulation of organic nutrient metabolism during transition from late pregnancy to early lactation. J. Anim. Sci. 73:2804-2819. https://doi.org/10.2527/1995.7392804x.

Blum, J. W., R. M. Bruckmaier, P.-Y. Vacher, A. M. Unger, and F. Jans. 2000. Twenty-four-hour patterns of hormones and metabolites in week 9 and 19 of lactation in high-yielding dairy cows fed triglycerides and free fatty acids. J. Vet. Med. A Physiol. Pathol. Clin. Med. 47:43-60. https://doi.org/10.1046/j.1439-0442.2000 $.00266 . x$.

Blum, J. W., F. Jans, W. Moses, D. Fröhli, M. Zemp, M. Wanner, I. C. Hart, R. Thun, and U. Keller. 1985. Twentyfour-hour pattern of blood hormone and metabolite concentrations in high-yielding dairy cows: Effects of feeding low or high amounts of starch, or crystalline fat. Zentralbl. Veterinärmed. A 32:401-418. https://doi .org/10.1111/j.1439-0442.1985.tb01957.x.

Cardoso, F. C., W. Sears, S. J. LeBlanc, and J. K. Drackley. 2011. Technical note: Comparison of 3 methods for analyzing areas under the curve for glucose and nonesterified fatty acids concentrations following epinephrine challenge in dairy cows. J. Dairy Sci. 94:6111-6115. https://doi.org/10.3168/jds.2011-4627.

Chapinal, N., M. Carson, T. F. Duffield, M. Capel, S. Godden, M. Overton, J. E. P. Santos, and S. J. LeBlanc. 2011. The association of serum metabolites with clinical disease during the transition period. J. Dairy Sci. 94:4897-4903. https://doi.org/10.3168/jds $.2010-4075$.

Chapinal, N., S. J. LeBlanc, M. E. Carson, K. E. Leslie, S. Godden, M. Capel, J. E. P. Santos, M. W. Overton, and T. F. Duffield.
2012. Herd-level association of serum metabolites in the transition period with disease, milk production, and early lactation reproductive performance. J. Dairy Sci. 95:5676-5682. https://doi.org/10 $.3168 /$ jds.2011-5132.

DeVries, T. J., M. A. G. Von Keyserlingk, and K. A. Beauchemin. 2003. Short communication: Diurnal feeding pattern of lactating dairy cows. J. Dairy Sci. 86:4079-4082. https://doi.org/10.3168/ jds.S0022-0302(03)74020-X.

Duffield, T. 2000. Subclinical ketosis in lactating dairy cattle. Vet. Clin. North Am. Food Anim. Pract. 16:231-253. https://doi.org/ 10.1016/S0749-0720(15)30103-1.

Eicher, R., A. Liesegang, E. Bouchard, and A. Tremblay. 1999. Effect of cow-specific factors and feeding frequency of concentrate on diurnal variations of blood metabolites in dairy cows. Am. J. Vet. Res. 60:1493-1499.

Heitmann, R. N., and J. M. Fernandez. 1986. Autoregulation of alimentary and hepatic ketogenesis in sheep. J. Dairy Sci. 69:12701281. https://doi.org/10.3168/jds.S0022-0302(86)80533-1.

Herrick, K. J., A. R. Hippen, K. F. Kalscheur, D. J. Schingoethe, D. P. Casper, S. C. Moreland, and J. E. van Eys. 2017. Singledose infusion of sodium butyrate, but not lactose, increases plasma $\beta$-hydroxybutyrate and insulin in lactating dairy cows. J. Dairy Sci. 100:757-768. https://doi.org/10.3168/jds.2016-11634.

Mahrt, A., O. Burfeind, and W. Heuwieser. 2014. Effects of time and sampling location on concentrations of $\beta$-hydroxybutyric acid in dairy cows. J. Dairy Sci. 97:291-298. https://doi.org/10.3168/jds .2013-7099.

Mashek, D. G., K. L. Ingvartsen, J. B. Andersen, M. Vestergaard, and T. Larsen. 2001. Effects of a four-day hyperinsulinemic-euglycemic clamp in early and mid-lactation dairy cows on plasma concentrations of metabolites, hormones, and binding proteins. Domest. Anim. Endocrinol. 21:169-185. https://doi.org/10.1016/S0739 $-7240(01) 00112-6$.

McArt, J., D. Nydam, and G. Oetzel. 2012. Epidemiology of subclinical ketosis in early lactation dairy cattle. J. Dairy Sci. 95:50565066. https://doi.org/10.3168/jds.2012-5443.

McArt, J., D. Nydam, and M. Overton. 2015. Hyperketonemia in early lactation dairy cattle: A deterministic estimate of component and total cost per case. J. Dairy Sci. 98:2043-2054. https://doi.org/10 $.3168 /$ jds.2014-8740.

McCarthy, M. M., S. Mann, D. V. Nydam, T. R. Overton, and J. A. A. McArt. 2015. Short communication: Concentrations of nonesterified fatty acids and $\beta$-hydroxybutyrate in dairy cows are not well correlated during the transition period. J. Dairy Sci. 98:6284-6290. https://doi.org/10.3168/jds.2015-9446.

Murondoti, A., R. Jorritsma, A. C. Beynen, T. Wensing, and M. J. H. Geelen. 2004. Unrestricted feed intake during the dry period impairs the postpartum oxidation and synthesis of fatty acids in the liver of dairy cows. J. Dairy Sci. 87:672-679. https://doi.org/ 10.3168/jds.S0022-0302(04)73210-5.

Nielsen, N. I., K. L. Ingvartsen, and T. Larsen. 2003. Diurnal variation and the effect of feed restriction on plasma and milk metabolites in TMR-fed dairy cows. J. Vet. Med. A Physiol. Pathol. Clin. Med. 50:88-97. https://doi.org/10.1046/j.1439-0442.2003.00496.x.

Oetzel, G. R. 2004. Monitoring and testing dairy herds for metabolic disease. Vet. Clin. North Am. Food Anim. Pract. 20:651-674. https://doi.org/10.1016/j.cvfa.2004.06.006.

Ospina, P. A., J. A. McArt, T. R. Overton, T. Stokol, and D. V. Nydam. 2013. Using nonesterified fatty acids and $\beta$-hydroxybutyrate concentrations during the transition period for herd-level monitoring of increased risk of disease and decreased reproductive and milking performance. Vet. Clin. North Am. Food Anim. Pract. 29:387-412. https://doi.org/10.1016/j.cvfa.2013.04.003.

Ospina, P. A., D. V. Nydam, T. Stokol, and T. R. Overton. 2010a. Associations of elevated non-esterified fatty acids and $\beta$-hydroxybutyrate concentrations with early lactation reproductive performance and milk production in transition dairy cattle in the northeastern United States. J. Dairy Sci. 93:1596-1603. https: //doi.org/10.3168/jds.2009-2852.

Ospina, P. A., D. V. Nydam, T. Stokol, and T. R. Overton. 2010b. Evaluation of nonesterified fatty acids and $\beta$-hydroxybutyrate in 
transition dairy cattle in the northeastern United States: Critical thresholds for prediction of clinical diseases. J. Dairy Sci. 93:546554. https://doi.org/10.3168/jds.2009-2277.

Sailer, K. J., R. S. Pralle, R. C. Oliveira, S. J. Erb, G. R. Oetzel, and H. M. White. 2018. Technical note: Validation of the BHBCheck blood $\beta$-hydroxybutyrate meter as a diagnostic tool for hyperketonemia in dairy cows. J. Dairy Sci. 101:1524-1529. https://doi.org/ 10.3168/jds.2017-13583.

Santschi, D. E., R. Lacroix, J. Durocher, M. Duplessis, R. K. Moore, and D. M. Lefebvre. 2016. Prevalence of elevated milk $\beta$-hydroxybutyrate concentrations in Holstein cows measured by Fourier-transform infrared analysis in Dairy Herd Improvement milk samples and association with milk yield and components. J. Dairy Sci. 99:9263-9270. https://doi.org/10.3168/jds.2016-11128.

Tatone, E. H., T. F. Duffield, S. J. LeBlanc, T. J. DeVries, and J. L. Gordon. 2017. Investigating the within-herd prevalence and risk factors for ketosis in dairy cattle in Ontario as diagnosed by the test-day concentration of $\beta$-hydroxybutyrate in milk. J. Dairy Sci. 100:1308-1318. https://doi.org/10.3168/jds.2016-11453.

White, H. M. 2015. The role of TCA cycle anaplerosis in ketosis and fatty liver in periparturient dairy cows. Animals (Basel) 5:793-802. https://doi.org/10.3390/ani5030384.

Xu, C., G. W. Liu, X. B. Li, C. Xia, H. Y. Zhang, and Z. Wang. 2010. decreased complete oxidation capacity of fatty acid in the liver of ketotic cows. Asian-Australas. J. Anim. Sci. 23:312-317. https:// doi.org/10.5713/ajas.2010.90416.

\section{ORCIDS}

C. R. Seely @ https://orcid.org/0000-0001-5201-1236

K. D. Bach ๑ https://orcid.org/0000-0003-2770-2574

D. M. Barbano @ https://orcid.org/0000-0002-0206-7028

J. A. A. McArt ๑ https://orcid.org/0000-0001-5654-9172 